\title{
Sample Return from Titan
}

\author{
Geoffrey A. Landis \\ NASA Glenn Research Center \\ 21000 Brookpark Road \\ Cleveland $\mathrm{OH} 44135$ \\ (216) 433-2238 \\ geoffrey.landis@nasa.gov \\ Steven R. Oleson \\ NASA Glenn Research Center \\ 21000 Brookpark Road \\ Cleveland $\mathrm{OH} 44135$ \\ steven.r.oleson@nasa.gov
}




\title{
Sample Return from Titan
}

\author{
Geoffrey A. Landis and Steven R. Oleson, NASA Glenn Research Center
}

\section{Introduction}

We propose that a Titan sample return mission would be possible in the next decade using insitu volatile propellants available on its surface.

Titan is scientifically fascinating in many ways, not the least of which is as a representative of the icy moons of the outer solar system, and a representative of the "water worlds" with liquid oceans under an ice shell. It is also the only body other than the Earth with a hydrological cycle (albeit with rains of methane taking the place of water in the phase-change cycle). Titan is also a high priority target for astrobiology. The surface and atmosphere are rich in the complex organic compounds known as tholins, which are ubiquitous in the outer solar system and Kuiper belt, yet not well understood. These are likely to be the molecules of the early solar system which served as the building blocks from life arose. Samples of Titan's surface and atmospheric tholins, as well as the many other components of Titan's surface, would be invaluable to understanding this relation. While some analysis of such compounds may be possible using lightweight instruments on board a probe, a detailed investigation of these complex compounds will require an analysis using a full laboratory on Earth. Sample return from Titan would thus have a high science value.

We wish to suggest here that it is possible to do this with credible technology, using In Situ Resource Utilization (ISRU) propellant production. While advances would still be needed in power, autonomy, mobility systems, and heat shields, these developments are not more difficult than similar efforts undertaken for Mars and lunar exploration, and we believe that a sample return mission from Titan could be feasible within the next decade.

\section{Background}

Titan is unique in the outer solar system in that it is the only moon with a thick atmosphere, and the only body in the solar system outside the Earth with liquid seas on its surface. The Titanian oceans, however, are not composed of water, like Earth's oceans, but are seas of liquid hydrocarbons. Not only does Titan possess hydrocarbons in their liquid state, but the Huygens probe discovered rocks of water ice laying upon the surface. With water and liquid methane and ethane easily available, Titan is a rocket scientist's dream for propellants, and Titan's low temperature makes them extremely easy to store once processed. Preliminary calculations show that as much as $4 / 5$ of the mass of a Titan sample return vehicle will comprise propellant. With the Dragonfly mission, Titan will have been scouted with an air-mobile rover. The next step is to return a sample.

\section{Why Titan? Scientific Value}

Titan is scientifically fascinating in many ways. As a world with an atmosphere and liquid oceans, and the only body other than the Earth with a hydrological cycle, Titan is a high value study for atmospheric and climate science, both in its own right, and also as an opportunity to learn about Earth by comparison to another, similar body. In addition, beneath a crust of ice, Titan is an ocean world, representative of the many ice-covered liquid oceans found in the solar system including moons of Jupiter, other moons of Saturn, Neptune, and even Pluto.

However, what is most interesting about Titan is that it is a high priority target for astrobiology. The Cassini/Huygens mission showed that it is a world with a surface covered in organic compounds protected with a thick nitrogen atmosphere (figures 1 and 2). The surface and 
atmosphere are rich in the complex organic compounds known as tholins, which are ubiquitous in the outer solar system and Kuiper belt, yet not well understood. Samples of Titan's surface and atmospheric tholins, as well as the many other components of Titan's surface, would be invaluable to scientists to discover how Titan came to be, and to give us samples to understand the organics of the outer solar system, giving valuable knowledge applicable to Earth's early environment and the organic precursors to life.

The importance of Titan for astrobiology has been noted by many researchers. Titan is listed as number one in the list of astrobiological targets by Shapiro and Schulze-Makuch (2009) due to its rich organic chemistry and the possibilities of understanding the early chemical stages that lead to life. Raulin (2008) emphasized the "many similarities with the prebiotic chemistry which allowed the emergence of life on Earth." Hörst et al. (2012) point out that the chemistry of Titan may emulate the prebiotic early Earth, and thus that studies of Titan chemistry could tell us about the conditions for the origin of life on Earth, a point also made in Raulin et al. (2009).

Many sources show that amino acids and nucleotides, the building blocks of life, can be formed in Titan conditions (including Hörst et al. (2012), Lorentz et al. (2005), Neish et al (2010), and Cleaves et. al (2015)).

\section{Benefit of Sample Return}
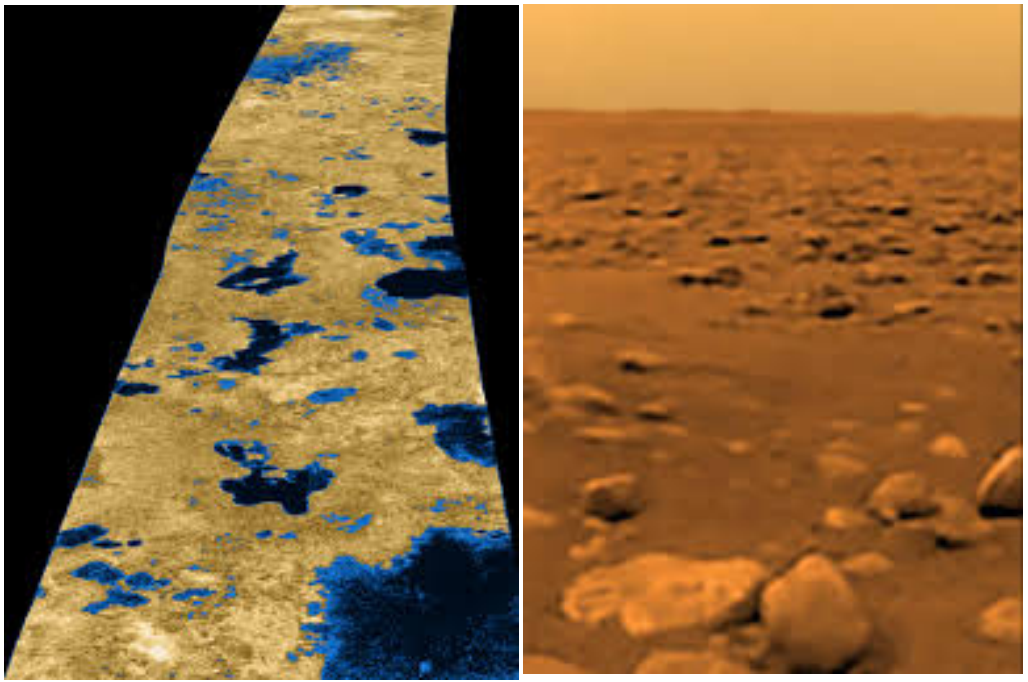

Figure 1: Titan's hydrocarbon lakes viewed by the Cassini radar.

Figure 2: the surface of Titan as viewed from the Huygens lander, showing the yellow-orange color associated with tholins, and surface

While some limited amount of analysis of such compounds may be possible using lightweight instruments on board a probe, a detailed understanding of the nature of these complex compounds will require an analysis using a full laboratory on Earth. Because of its value to understanding the organic compounds of the outer solar system which may be the primordial building-blocks of life, return of samples from Titan to laboratories on Earth will be the primary goal of this mission.

Sample return from Mars has long been proposed as the most important, but most ambitious, next step for scientific understanding of the solar system and of the origin of life. Unlike Mars, however (on which only trace amounts of simple organic compounds have been found), Titan is known to have complex organic molecules on the surface. We suggest that a sample return of these compounds will tell us more about organic molecules in the solar system, and the origin of life, than a sample from Mars.

Such a sample return would truly be "mission incredible". But to date, a sample return mission from so distant a target has been assumed, without game-changing improvements in technology, to be mission impossible. We believe that the use of ISRU can render this mission feasible within the decade.

\section{Mission}

While a concept of returning samples from Titan would give unprecedented science return, to 
return even a small sample from Titan using conventional technology would be tremendously difficult. Saturn is at a distance of almost a billion miles from the Earth, about thirteen times farther than Mars. A return mission to Saturn would require such a large total-mission $\Delta \mathrm{V}$ that, with conventional technology, the mass ratios required for the mission would be prohibitive.

At first glance, it would seem to be a step too far to propose a sample return from Titan, when even returning samples from Mars, thirteen times closer in $\Delta \mathrm{V}$, is a flagship-class project that has never been done. However, we point out that Titan has two significant attributes that can be used to reduce the mission $\Delta \mathrm{V}$. First, it has a thick atmosphere-- 1.5 times the atmospheric pressure of Earth-- that allows us to use aerobraking to reduce the entry velocity, and a parachute for soft landing. Unlike Mars landers, a mission to Titan will not need a final rocket-powered descent stage. Second, and more important, Titan has abundant resources for producing rocket fuel. Titan is known to have surface lakes of liquid methane and ethane, totaling an amount of hydrocarbons larger than the total fossil fuel reserves of the Earth. And Titan has surface rocks of water ice, which is a source of oxygen. With both hydrocarbons and oxygen, as discussed below, we have the ability to produce fuel. In addition, the environment of Titan turns out to be ideal to store the fuel.

Titan also has the advantage of being in orbit around a high-mass planet, Saturn, which gives us the ability to use the gravity well of Saturn to improve the efficiency of the braking burn to enter and leave the Saturn system (the "Oberth effect").

In-situ resource utilization (ISRU) for propellant production is an approach that proposes using the local resources of the planetary environment being explored as an alternative to bringing fuel from Earth. ISRU has been explored as a technology for Mars sample return and human missions, but has not been analyzed for missions farther out in the solar system. As will be seen, propellent production from resources on Titan is significantly different than the concepts proposed for Mars.

Our calculations suggest that a sample could be returned using the resources of Titan to produce in-situ fuel at about one fifth of the estimated mass (and cost) it would take to do the mission with conventional technology.

\section{Technology}

\section{Potential In-Situ Propellants}

Titan is rich in volatiles: methane/ethane seas, a dense nitrogen atmosphere, and water 'rocks'. Chemical rocket propellant consists of a fuel and oxidizer combination. The obvious choice for fuel is the native Titan hydrocarbon. Methane and ethane are abundant on Titan, available in liquid form in lakes on the surface, and can be used either as a mixture of methane and ethane, or distilled to pure methane. Unlike any other destination in the solar system, producing rocket fuel on Titan needs no chemical processing: it requires nothing more than a pipe and a pump.

On Titan, the more difficult choice is the oxidizer. For this mission we propose refining oxygen from Titan's rocks, which are made of water ice. The rocks are gathered up, melted using the heat from the radioisotope source, and electrolyzed to produce oxygen. Titan's ambient temperature makes storage of oxygen in the form of liquid oxygen (LOX) fairly easy.

The combination of methane and LOX is very nearly the ideal rocket propellant. The specific impulse (Isp) of 325 seconds is second only to liquid hydrogen/oxygen ("LH2/LOX") among the hydrocarbon-based rocket fuels, but methane's much higher density than hydrogen $\left(0.44 \mathrm{~kg} / \mathrm{m}^{3}\right.$, compared to LH2 at 0.071), allows for considerably smaller tanks, and eliminates the requirement 
for cryogenic storage. For these reasons, methane/oxygen engines are being developed for the next generation of launch vehicles, including the SpaceX Starship, the Blue Origin New Glenn, and the ULA Vulcan. The development of these vehicles (and others) means that engines which have already been designed and tested will be available for this project.

An alternate possibility is to use liquid ethane, which is also available at Titan, with a slightly higher density, $0.65 \mathrm{~kg} / \mathrm{m}^{3}$, but a lower specific impulse. A mixture of ethane and methane could also be used. A final possibility is to use hydrogen. In our baseline system, the water electrolysis will produce hydrogen that is vented as surplus, but an alternative approach would be to use a LOX/LH2 engine, at $>430 \mathrm{~s}$ Isp. This is not likely to be the optimum solution for the booster stage required to launch from the surface, because of the low density and difficulty of storage, but could be a possible high-Isp choice for one or both of the smaller Earth return stages, for which specific impulse becomes most important. However, storing the LH2 is more difficult, and would require a thermally insulated storage system and a cryocooler to keep the hydrogen liquid, at about $30 \mathrm{~K}$. While methane/LOX is proposed as the baseline choice for all three stages, all the possibilities should be compared in a detailed design study.

\section{ISRU-Fueled Launcher Estimated Performance}

A rough calculation was performed to see just how much propellant is needed to return samples to the Earth. From Dankanich and Oleson (2008), ascent and Earth-return $\Delta$ Vs required are around $3300 \mathrm{~m} / \mathrm{s}$ and $4600 \mathrm{~m} / \mathrm{s}$ respectively. Similar values are calculated by Donahue (2010). Table 1 shows the roughly estimated launcher performance, assuming a 60-kg Earth return vehicle (12 $\mathrm{km} / \mathrm{s}$ hyperbolic arrival velocity) similar to Stardust and an $80 \mathrm{~kg}$, powered cruise deck powered by a radioisotope generator. While the three-stage vehicle's mass is quite large, since the mission will acquire over $3500 \mathrm{~kg}$ of propellants from Titan, only around $1000 \mathrm{~kg}$ need to be landed. This is within the mass that has already been demonstrated for aero-entry on Mars.

An alternative option would be to keep the cruise system in orbit, to minimize the mass to be landed on Titan; this option was not analyzed. Regardless, the Earth-return propellant is far more economically generated on Titan than brought from Earth.

While the landed mass is low, the propellant volume would be very high. To minimize the volume required in the entry vehicle, options of expandable or inflatable tanks (fig 4) should be explored.

This set of parameters should be considered a proof-of-concept numbers showing that the mission is feasible, not a design solution. The vehicle has not been optimized. For example, using a three-burn approach to the Saturn system escape could lower the mission $\Delta \mathrm{V}$ or decrease the flight

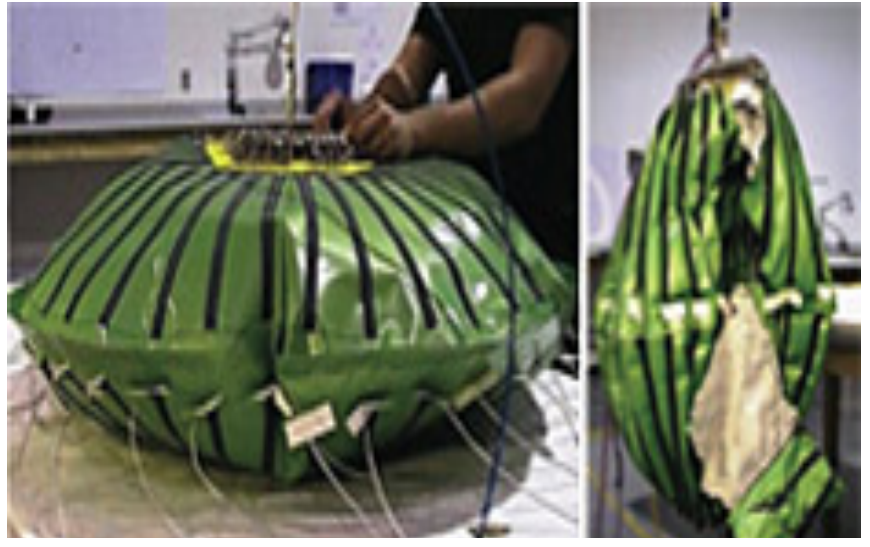

Fig. 3. Lightweight Inflatable Cryogenic Tank (NASA/KSC). time by utilizing the Oberth effect of a close Saturn pass to increase the trans-Earth injection C3. Such trajectory optimizations would be analyzed in a trade-study in the detailed design. We can also use a Jupiter gravity assist, although this puts constraints on the launch window. The Jupiter slingshot can be used to reduce the $\Delta \mathrm{V}$ or the flight time on either the outbound leg of the mission, or for the Earth return. (Using the Jupiter slingshot for both outbound and inbound is possible, but 
would require increasing the mission time by more than ten years, to wait for the required Jupiter/Saturn alignment, which is not desirable). The present concept assumes a Jupiter fly-by for the outbound leg, which puts the optimum launch window near 2037.

\begin{tabular}{|c|c|c|c|c|c|c|}
\hline & $\Delta \mathrm{V}(\mathrm{m} / \mathrm{s})$ & Mo & Stage mass & $\begin{array}{l}\text { Burnoutm } \\
\text { ass }\end{array}$ & $\begin{array}{l}\text { Pro- } \\
\text { pellant }\end{array}$ & $\begin{array}{l}\text { Final mass less } \\
\text { stage }\end{array}$ \\
\hline Ascent stage 1 & 3300 & $4500 \mathrm{~kg}$ & $576 \mathrm{~kg}$ & $1619 \mathrm{~kg}$ & $2881 \mathrm{~kg}$ & $1042 \mathrm{~kg}$ \\
\hline Return Stage 1 & 1380 & 1042 kg & $73 \mathrm{~kg}$ & $680 \mathrm{~kg}$ & $363 \mathrm{~kg}$ & $607 \mathrm{~kg}$ \\
\hline Return Stage 2 & 3220 & $607 \mathrm{~kg}$ & $77 \mathrm{~kg}$ & $224 \mathrm{~kg}$ & $383 \mathrm{~kg}$ & $147 \mathrm{~kg}$ \\
\hline & & $\begin{array}{l}\text { Dry Launcher } \\
\text { Mass (less }\end{array}$ & & $\begin{array}{l}\text { ISRU } \\
\text { Propellant }\end{array}$ & & \\
\hline $\begin{array}{l}\text { Payload Mass } \\
\text { Assumptions }\end{array}$ & $147 \mathrm{~kg}$ & payload) & $873 \mathrm{~kg}$ & Mass & $3627 \mathrm{~kg}$ & \\
\hline Isp & 329 & s & & & & \\
\hline Ascent & 3300 & $\mathrm{~m} / \mathrm{s}$ & & & & \\
\hline return & 4600 & $\mathrm{~m} / \mathrm{s}$ & & & & \\
\hline Stage Fraction & 0.2 & & & & & \\
\hline Launcher Initial Mass & 4500 & $\mathrm{~kg}$ & & & & \\
\hline Sample return capsule & 60 & $\mathrm{~kg}$ & & & & \\
\hline Return Cruise system & 80 & & & & & \\
\hline
\end{tabular}

Table 1: $\Delta \mathrm{V}$ and mass fraction for Titan sample return launch, showing the fueled mass (Mo) and the burnout mass (Mf) of each stage

\section{Propellant Acquisition}

Landing close to a Titan sea would make methane acquisition simple, requiring little more than a pipeline and a pump. A rover to collect water rocks and samples would complete the propellant acquisition. The rate-limiting step to propellant processing will be electrolysis of the water to produce the required oxygen. This processing will require power, provided by a radioisotope power system, assumed here to be the Advanced Stirling radioisotope generator (ASRG). In this case, the efficiency of the power conversion will be increased by the low ambient temperature; the waste heat from the ASRG can be used to melt the water, while electrical power is used to electrolyze the water into hydrogen (assumed to be discarded) and oxygen. Alternatively, if a higher propellant processing rate is desired, power could be provided by a reactor power systems such as the "Kilopower" reactor that is now being developed for other missions [12].

\section{Cryogenic Storage}

ISRU propellant for sample return is made simpler on Titan because the ambient temperature on Titan is ideally suited for the propellants we will be using. The surface temperature on Titan is about $90.6 \mathrm{~K}\left(-179{ }^{\circ} \mathrm{C}\right)$, with a maximum measured temperature of $93.6 \mathrm{~K}\left(-179.6^{\circ} \mathrm{C}\right)$. This is just above methane's freezing point at Titan's atmospheric pressure (which is not unexpected, since methane is liquid in the Titan lakes), allowing us to store the methane as a liquid fuel with no refrigeration. The temperature is very close to the $90.2 \mathrm{~K}$ boiling point of liquid oxygen at 1bar pressure, but the high pressure of Titan's atmosphere means that by maintaining about 1-bar above ambient pressure in the tank, the oxygen remains liquid up to $100 \mathrm{~K}$, a comfortable margin above the highest temperature measured on Titan. Thus, by a fortunate coincidence, the temperature and pressure at the surface of Titan is exactly right to allow both methane and oxygen to be stored in liquid form without refrigeration. Likewise, if we chose to use ethane as the fuel, accepting a slightly lower specific impulse but a higher density and hence smaller tanks, ethane is also liquid at Titan temperatures. 


\section{Summary}

Titan is a moon rich in scientific interest and volatiles. We propose that a mission to return a sample from the surface of Titan would be of great scientific interest, bringing back organic samples from a destination an order of magnitude farther away than Mars, and in the process demonstrating a propellant concept that will have wide-ranging applications for other space missions. Nevertheless, despite its unprecedented scientific value and groundbreaking technologies, the project is technically credible: the physical principles behind the system are well understood.

Despite the greater distance to Titan than to the Moon or Mars, we argue that this ISRU system is actually easier to do, and yet has significantly higher performance, than the more complicated chemical-reduction processes previously proposed for Mars and the Moon. Although some technology development would be required, we believe that such a mission could be easily accomplished in the next decade.

\section{References}

1. S. MacKenzie, et al., "Titan: Earthlike on the Outside, Ocean World on the Inside," white paper submitted to the Planetary Science Decadal Survey, July 2020.

2. R.D. Lorenz, J. Lunine, W. Zimmerman, "Post-Cassini exploration of Titan," Adv. Space Research, 36, 2 (2005) pp. 281-285.

3. F. Raulin, "Astrobiology and habitability of Titan," Space Sci. Rev. 135, pp. 37-48 (2008)

4. F. Raulin, C. McKay, J. Lunine, and T. Owen, "Titan's Astrobiology". In: Brown R.H., Lebreton J.P., Waite J.H. (eds) Titan from Cassini-Huygens. Springer, Dordrecht. (2009).

5. R. Shapiro and D. Schulze-Makuch, "The Search for Alien Life in Our Solar System: Strategies and Priorities," Astrobiology, 9, No. 4 (11 Jun 2009).

6. N. Sarker, et al., "Titan Aerosol Analogues: Analysis of the Nonvolatile Tholins," Astrobiology, 3, No. 4 (July 5, 2004) pp. 719-726.

7. C.D. Neish, Á. Somogyi, and M.A. Smith, "Titan's Primordial Soup: Formation of Amino Acids via Low-Temperature Hydrolysis of Tholins," Astrobiology, 10, No. 3 (April 2010) pp. 337-347.

8. S.M. Hörst, et al., "Formation of Amino Acids and Nucleotide Bases in a Titan Atmosphere Simulation Experiment," Astrobiology, 12, No. 9 (Sept. 2012) pp. 809-817.

9. H.J. Cleaves II, et al., "Amino acids generated from hydrated Titan tholins: Comparison with Miller-Urey electric discharge products", Icarus, 237 (July 15, 2014) pp. 182-189.

10. J.W. Dankanich and S.R. Oleson, "Radioisotope Electric Propulsion (REP) Centaur Orbiter Mission Design," paper AIAA 2008-4518, 44th AIAA/ASME/SAE/ASEE Joint Propulsion Conference \& Exhibit, Hartford, CT (21-23 July 2008).

11. B. Donahue, "Titan Sample Return Mission Concept", 57th JANNAF Propulsion Meeting, Colorado Springs, CO (May 2010).

12. M. A. Gibson, et al. "NASA's Kilopower reactor development and the path to higher power missions," 2017 IEEE Aerospace Conference, Big Sky, MT (Mar. 4-11, 2017). 